all of Natal, South Africa. The aviaries are of simple wire-netting, in which are growing flowering shrubs and weeds. Their dimensions are $12 \times 9 \times 6 \mathrm{ft}$.

The food provided is Mellin's (baby) food, honey, and Swiss milk (tin) in equal proportions, and peaflour one-quarter to the above.

The brilliant scarlet borne by certain of the varieties has changed in every case to a bright orange colour, thus causing the bird to present a great contrast to its original colour. Metallic green, which is borne by so many of the "sun-birds," is in no manner affected. Other colours of these birds are also not affected.

It would appear to be a case of change of plumage caused by the feeding, for the condition of life is almost natural.

We are not aware of such variety of colour having been observed previously. It would be of interest if any contributor to NATURE could give information of examples of similar occurrences with respect to captive wild birds, or offer an explanation of the physiological causes which are at work.

$$
\text { HaRold Millar, }
$$

Director.

Zoological Gardens, Mitchell Park, Durban,

Natal, December 30, I9I9.

\section{MATHEMATICS IN THE UNITED STATES.}

NOT very long ago (perhaps fifteen or twenty years) an English lady, spending a visit in Utrecht, met a distinguished Dutch professor of mathematics. In the course of conversation the lady asked the professor what he thought of contemporary English mathematicians and their work. The answer was not calculated to flatter our national vanity, for it was to the effect that he rarely looked at English mathematical papers, because they were so unconnected with the general progress of the science, and written in such a peculiar way that he could scarcely understand them. Incredible as it seems, this opinion was expressed when Salmon, Cayley, Sylvester, and Clifford had published all their best work. Prejudices die hard, and the professor's attitude would have been intelligible in the earlier part of the nineteenth century.

One moral of the story is that, as there are nationalities in drinks, so there are in mathematics, in spite of the growing tendency towards universal co-operation. The history of recent mathematical progress in the United States presents many points of interest. To a great extent, American mathematicians may be regarded as the grown-up pupils of Germany. From Germany they have acquired habits of thoroughness, breadth of view, and collaboration. But they have clearly passed the time of pupilage, as we see from their growing list of original and eminent writers; it is enough to refer to such men as the two Peirces and Willard Gibbs.

There are several features of the attitude of the Americans towards mathematics which deserve our careful attention. In the first place, it should be noted that the State and private benefactors encourage mathematics for its own sake, quite apart from considerations of utility. Many AmeriNO. 2623 , VOL. IO4] can professors are allowed to devote themselves to research in such things as group-theory, abstract geometry of all kinds, function-theory, and the higher arithmetic; the predominance of such subjects in American journals and transactions is quite remarkable. The Government and people of the United States appear to be fully conscious of the fact that special ability of every kind should be encouraged.

An excellent American institution, which might well be adopted here, is that of the sabbatical year, which gives the teacher an opportunity of bringing his knowledge up to date, or of carrying out some laborious research. As an example of what can be done in such periods of leisure, we may refer to the recently published first volume of Prof. L. E. Dickson's "History of the Theory of Numbers." With almost incredible industry, the author has personally consulted and summarised thousands of papers, notes, and memoirs; and if the work is carried out on the same scale it will fill four or five large octavo volumes, and be an indispensable guide to all who work in this field. It may be remarked here that we owe to the States many valuable works on the history of mathematics (especially from the teacher's point of view), and reprints and translations of scarce and valuable works.

Collaboration, both in the composition of books and in that of papers, is more common than with us. There are two sides to this question; in some cases the advantages of joint authorship are obvious, but those treatises which rank as masterpieces (such as Salmon's "Conic Sections" or H. Weber's "Algebra") are usually, if not always, the work of one man.

American mathematical colloquia are far more serious affairs than anything we have here. They are meetings of experts, lasting for a week or so, at which a serious programme is carried out, and carefully prepared addresses and short sets of lectures are delivered on topics of outstanding interest. In this matter we ourselves seem to vibrate between two extremes; either we have a technical meeting where papers are read (or taken as read), which seldom interest more than one or two of the audience, or we indulge in a picnic, at which a few casual notes are communicated, mainly for the sake of securing priority.

While thus directing attention to some things in which we might well imitate the States, we have no intention of carping at our own country. men. The general condition of mathematics in this country is probably better now than it has been for many years, and we should be sorry to see some of the old English characteristics disappear. For instance, the view that mathematics is a gentlemanly recreation has something to be said for it, and we may avoid being needlessly solemn and serious in our study of it, however conscious we may be of its vital importance for national welfare.

G. B. M. 